\title{
Performance Analysis of Flexible Ink-jet Printed Humidity Sensors Based on Graphene Oxide
}

\author{
Dragana Vasiljevic, Member, IEEE, Aida Mansouri, Luca Anzi, Roman Sordan, Goran Stojanovic, \\ Member, IEEE
}

\begin{abstract}
This paper presents design, fabrication and characterization of flexible capacitive graphene oxide (GO) based humidity sensors, which can be used in many applications, such as environmental protection, civil engineering, and agriculture. They consist of interdigitated electrodes ink-jet printed on a polyimide flexible substrate and GO based sensing layer. Measurement setup for testing and characterization was developed in laboratory conditions. The dependence of the capacitance and resistance of the GO based humidity sensors on the percentage of the applied humidity is presented. The main advantage of developed GO based capacitive humidity sensors is very large variation of capacitance, almost five orders of magnitude, compared to the previously demonstrated sensors. The other advantages of the sensors are fast response-recovery time, excellent reproducibility of the measurement results and use of cost-effective additive ink-jet technology.
\end{abstract}

Index Terms - capacitive sensor, graphene oxide, humidity sensor, ink-jet printing

\section{INTRODUCTION}

$\mathrm{D}$ UE to their high sensitivity, low power consumption, and fabrication costs, humidity sensors play an important role in many measurement and control applications, including meteorology, agriculture, industrial control, and medical instrumentation [1-4]. In the past years, a lot of effort has been made to develop high performance humidity sensors [5-8], exhibiting large sensitivity, fast response and recovery [9-10], and small humidity hysteresis. Various transduction techniques, such as capacitive, resistive, acoustic, optical and mechanical, have been adopted for the design of humidity sensors. Novel sensing materials, such as graphene oxide (GO), have recently been introduced in humidity sensors [1121].

This work was supported by the Central European Initiative (CEI), (Grant No. 1206.011-14) CEI Know-how Exchange Programme, EU H2020 Graphene Flagship Core 1 Project 696656 and partly supported by the Project no. 142-451-2484/2017-01/01 founded by the Provincial Secretariat for Higher Education and Science of The Province of Vojvodina and Ministry of Education, Science and Technological Development of Serbia within the project no. TR32016.

D. V. and S. G. Authors are with the University of Novi Sad, Faculty of Technical Sciences, Trg Dositeja Obradovića 6, Novi Sad 21000, Serbia (emails: vdragana@uns.ac.rs and sgoran@uns.ac.rs).

A. M., L. A. and R. S. Authors are with the L-NESS, Department of Physics, Politecnico di Milano, Polo di Como, Via Anzani 42, 22100 Como, Italy (e-mails: aida.mansouri@polimi.it, luca.anzi@polimi.it and roman.sordan@polimi.it).
For instance, the sensitivity of complementary-metal-oxidesemiconductor (CMOS) interdigital capacitive humidity sensors has been significantly improved by using $\mathrm{GO}$ as a sensing material [22]. However, some of the GO based sensors have been made by complex and costly fabrication techniques, such as etching [18] or layer-by-layer deposition [16]. The humidity sensors based on gold nanoparticles and GO have been fabricated by a combination of self-assembly and the sol-gel technique [23]. Spin-coating chemically derived GO on a quartz crystal microbalance have been used to fabricate humidity sensors in which the frequency response of the microbalance depended on the relative humidity (RH) [24]. Uniform GO films deposited by a dip-coating technique have been used for optical humidity sensing [12].

It has been widely acknowledged that ink-jet fabrication technology is a cost-effective method for manufacturing humidity sensors $[25,26]$. Ink-jet printed GO has been used in temperature-modulated resistive humidity sensors which employ CMOS micro-electro-mechanical-system microhotplate technology for the monitoring and control of indoor air quality [27]. Thin-film chemiresistors, made of a thin film composed of overlapped and reduced GO (rGO) platelets, were printed onto flexible plastic surfaces by using ink-jet technique [28]. However, in order to achieve the required sensitivity, the demonstrated sensors needed a large number of printed interdigitated electrodes on the substrates, i.e., a large area of the sensor chip.

Here we demonstrate GO based capacitive humidity sensors fabricated on flexible substrates, with very large variation of capacitance with percentage of applied RH. As a result of the extraordinary sensing properties of GO, the occupied area of the sensor chip was reduced with respect to the GO-free sensors which had more electrodes. The sensing was carried out for RH between $55 \%$ and $95 \%$. The main advantage of the developed sensors compared to the previously demonstrated sensors is their remarkable sensitivity because the change of the measured capacitances was $\sim 5$ orders of magnitude. The other advantages are fast response-recovery time, excellent reproducibility of the measurement results and use of cost-effective additive ink-jet technology, which allowed scalable production of the sensors. Mechanical flexibility of the sensors is also one of the very important advantages which allows installation of the sensor and measuring humidity in uneven and inaccessible places. 


\section{DESIGN AND FABRICATION}

The fabricated sensors were prepared by ink-jet printing process, using Dimatix deposition material printer (DMP3000) and spin coating. An interdigitated capacitor with 20 pairs of electrodes was designed, as shown in Fig. 1. It consists of a polyimide substrate, interdigitated Ag electrodes and sensing GO material.

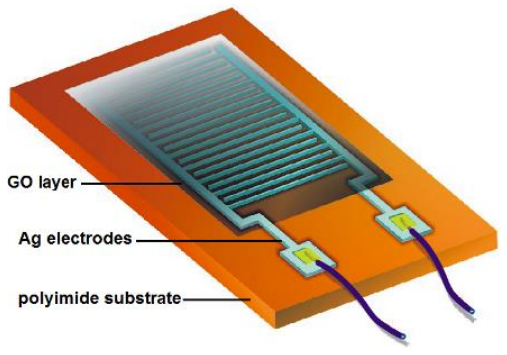

(a)

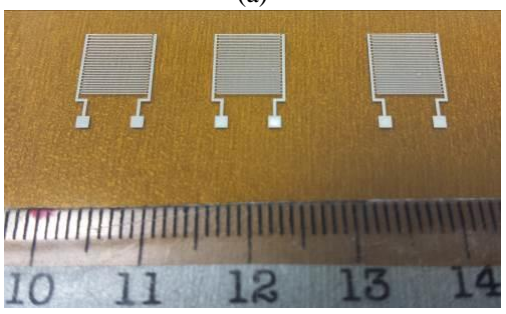

(b)

Fig. 1. Capacitive humidity sensor based on GO (a) Schematic of the sensor. (b) Sensor's electrodes before deposition of GO. The ruler is in $\mathrm{cm}$.

The length of each electrode was $7 \mathrm{~mm}$, while the electrode width and spacing were $100 \mu \mathrm{m}$, which was within the resolution limit of the used ink-jet printer. The first sensor layer was fabricated by printing commercially available SunChemical Ag nanoparticle ink with $20 \mathrm{wt} \%$. The thickness of the GTS polyimide film in the active area was $75 \mu \mathrm{m}$ [29]. The resolution of the ink-jet process using DMP-3000 was mainly limited by the nozzle diameter (approximately equal to the droplet diameter) and the statistical variation of the droplet flight and spreading on the substrate. In case of printing with Ag nanoparticle ink, the minimum droplet diameter was $\sim 36$ $\mu \mathrm{m}$, and center-to-center drop spacing was $18 \mu \mathrm{m}$, which was obtained by changing the printhead angle [30]. Three structures with the same active area were printed and sintered at $240{ }^{\circ} \mathrm{C}$ for $30 \mathrm{~min}$. Although the designed width of the electrodes was $100 \mu \mathrm{m}$, the printed lines shrunk to $90 \mu \mathrm{m}$ after printing and $\sim 80 \mu \mathrm{m}$ after sintering.

The second sensor layer was fabricated by spin coating 3 layers of commercially available Graphenea graphene oxide ink, with a concentration of $0.4 \mathrm{wt} \%$, on top of the electrodes at $750 \mathrm{rpm}$ for $5 \mathrm{~s}$ and then at $1500 \mathrm{rpm}$ for $40 \mathrm{~s}$. Monolayer content in the ink was $>95 \%$ at $0.05 \mathrm{wt} \%$. The samples were dried at $100{ }^{\circ} \mathrm{C}$ for $30 \mathrm{~min}$ and then cooled to room temperature.

Proper deposition of GO was firstly verified by an optical microscope. Fig. 2 shows optical microscope images of sensor electrodes before and after spin coating of GO ink.

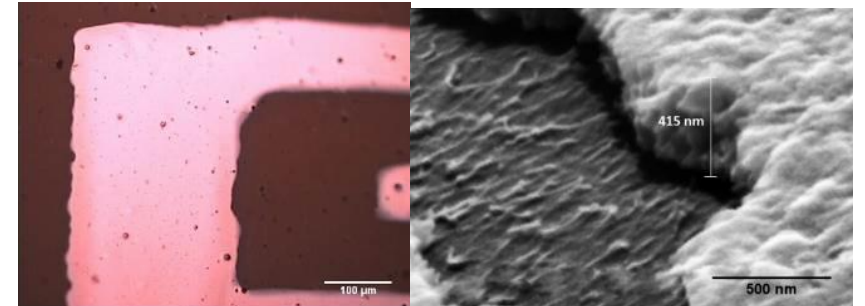

(a)

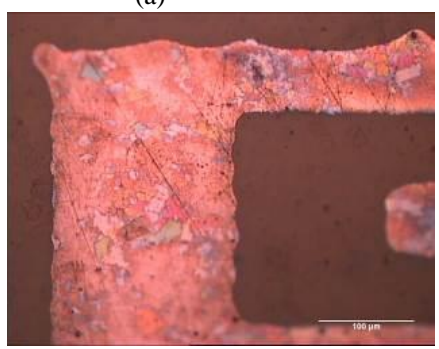

(c) (b)

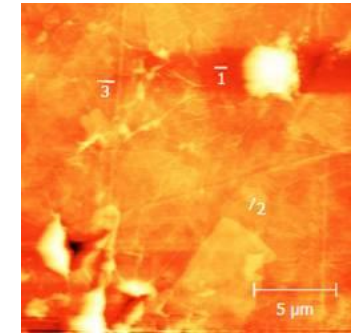

(d)

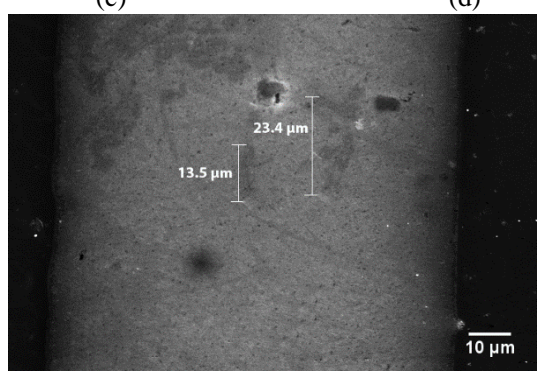

(e)

Fig. 2. Sensor Ag electrodes without and with the GO film. (a) An optical microscope image of bare sensor electrodes. (b) A tilted scanning electron microscope (SEM) image of a bare sensor electrode showing a typical thickness of $\sim 400 \mathrm{~nm}$ of the printed Ag layer. (c) An optical microscope image of sensor electrodes after spin coating GO ink. (d) An AFM image of the GO film deposited on the electrodes. A topography analysis along the sections 1, 2 and 3 indicated in the image reveals typical thickness of the GO flakes of $\sim 9 \mathrm{~nm}$, (e) A top view SEM image of the sensor electrode showing a lateral dimension of deposited GO flakes of $\sim 10 \mu \mathrm{m}$.

The presence of the GO flakes on top of the Ag electrodes is clearly visible in the latter case. The thickness of GO flakes was also verified by atomic force microscope (AFM) characterization, as it is shown in the same figure. The thickness of the GO flakes was $\sim 9 \mathrm{~nm}$ which confirmed successful deposition. The thickness of the Ag layer and the lateral dimensions of the flakes were $\sim 400 \mathrm{~nm}$ and $\sim 10 \mu \mathrm{m}$, respectively, as shown in Fig. 2(b) and 2(e). The thickness of the GO layer was not uniform over the whole active area due to limitations of spin coating technology. AFM measurements showed multiple GO flakes agglomerated at some areas of the sensors.

Different geometries of the Ag electrodes were printed in order to understand whether they have influence on the spin coating of GO. We found that the spin coating process was mainly unaffected by the electrode design.

\section{RESULTS AND DISCUSSION}

Measurements were performed using in-house measurement setup, illustrated in Fig. 3. It consists of a chamber (plastic box) and humidity source (aerosol). Capacitance and resistance of the fabricated sensors were measured using Agilent LCR meter 4284A. Commercially available Omega 
RH USB probe with a temperature sensor was also placed in the chamber and used as a reference [31].

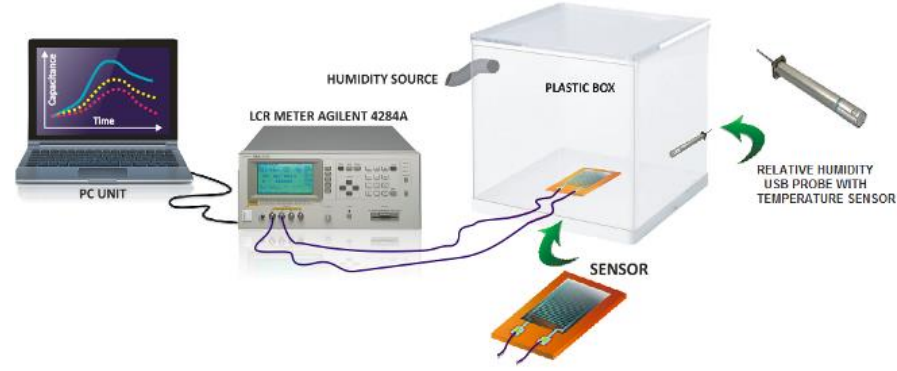

Figure 3. Schematic of a humidity sensing measurement setup

The capacitance and resistance of all 3 sensor samples were measured as a function of time while changing the $\mathrm{RH}$ as follows. The sensor was placed in the chamber with laboratory atmosphere at room temperature, and its stable output was recorded. The humidity source was then turned on and it was kept running for 9 min after which the steady state with 95 $\%$ RH was reached, as determined by the commercial sensor placed in the same chamber. Finally, the humidity source was turned off and the sensor was exposed to laboratory atmosphere again. The measurements were initially performed at three different frequencies: 1,10 and $100 \mathrm{kHz}$. The highest sensitivity was obtained at $1 \mathrm{kHz}$, which was then used in all present measurements. Fig. 4(a) shows the results obtained by measuring the capacitance of the sensors, without and with the GO film, under such conditions. In sensors without the GO film, the capacitance increased $\sim 10$ times in the humidity range from $55 \% \mathrm{RH}$ to $95 \% \mathrm{RH}$, but it did not exceed $120 \mathrm{pF}$. However, in sensors with the GO film, Fig. 4(b), the capacitance increased by almost five orders of magnitude, from $43 \mathrm{pF}$ to $1.6 \mu \mathrm{F}$, in the same humidity range. The difference in the Omega sensor response, which can be observed by comparing Fig. 4(a) and (b), is a consequence of the drying process which was simply done by exposing the sensors to ambient air. This probably left some residual humidity in the sensing area of the Omega sensor.

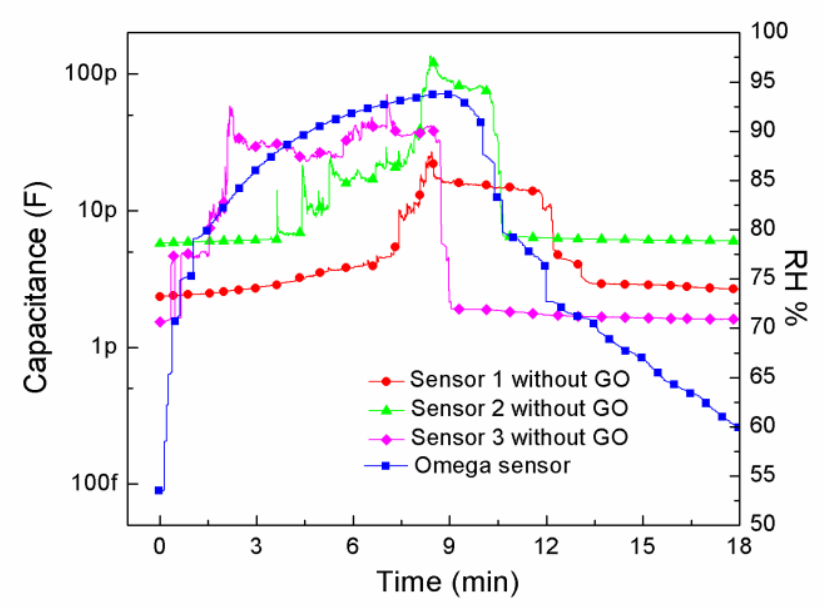

(a)

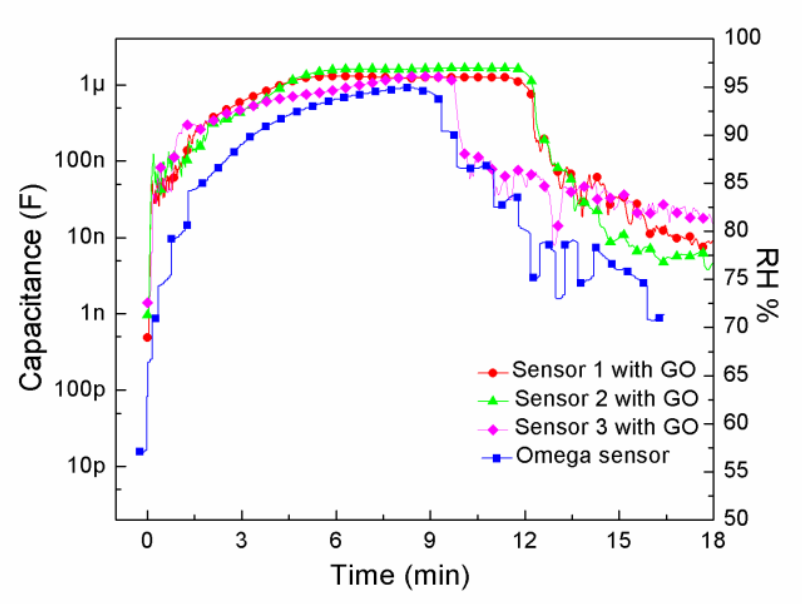

(b)

Fig. 4. Capacitance of 3 different sensors (encoded in different colors) as a function of time. (a) Sensors without the GO film. (b) Sensors with the GO film. In both cases humidity was changed from $55 \% \mathrm{RH}$ to $95 \% \mathrm{RH}$ and then back to $55 \% \mathrm{RH}$. The blue curves (with the scale on the right) show the RH measured by the commercial sensor at the same time.

The obtained results can be explained by the expression for the capacitance of the sensing material [32].

$$
C=\varepsilon^{*} C_{0}=\left(\varepsilon_{r}-\frac{i \gamma}{\omega \varepsilon_{0}}\right) C_{0}
$$

where $\varepsilon^{*}$ is the complex dielectric constant of the material, $C_{0}$ is the capacitance of the vacuum capacitor with the same dimensions as the sensing layer, $\varepsilon_{r}$ is the relative dielectric constant of the material, $\varepsilon_{0}$ is the vacuum permittivity, $\gamma$ is the leak conductance, and $\omega$ is the angular frequency. This shows that the capacitance of the sensing material is proportional to $\gamma$. With the increase of $\mathrm{RH}$, water molecules are physisorbed through single hydrogen bonding on the hydroxyl groups in GO [11]. When exposed to the external electric field, the water molecules undergo protonation (due to a transfer of oxygen from the large number of oxygen-containing groups in GO, e.g., epoxy groups) and yield a large number of hydronium ions $\left(\mathrm{H}_{3} \mathrm{O}^{+}\right)$which act as charge carriers [11]. Because of this, the increase of RH increases $\gamma$ which increases the capacitance. A very good sensitivity, observed here at large $\mathrm{RH}$, is due to the physisorbed water layers behaving as liquid which allows hydronium ions to freely move and contribute to the ionic conduction [11]. Large surface area of the GO flakes is also beneficial for increasing the sensitivity of the sensors, which ultimately depends on the film thickness and its uniformity. For instance, we found that the GO film was not uniform over the entire active area due to the limitations of the spin coating process. Agglomerates of the GO flakes were found in many places leading to the increase of sensitivity. The different humidity response of different sensors can also be attributed to the nonuniformity of the GO film. 


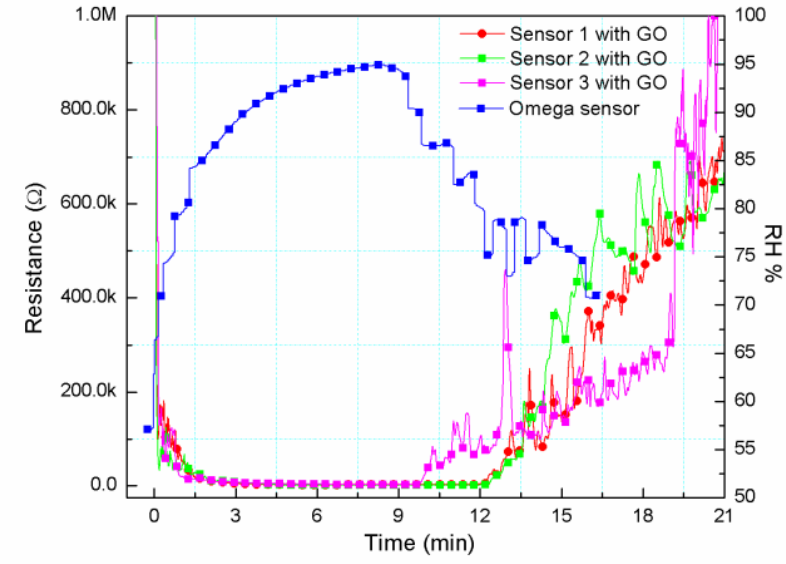

Fig. 5. Resistance of 3 different sensors (encoded in different colors) with GO as sensing material. The resistances were measured at the same time as the capacitance of the sensors shown in Figure 4b. The blue curve (with the scale on the right) shows RH measured by the commercial sensor at the same time.

Fig. 5 shows the time dependence of the resistance of the fabricated GO sensors recorded at the same time as the capacitances shown in Fig. 4(b). In the previous reports [33], the change of resistance has been from $300 \mathrm{k} \Omega$ to $20 \mathrm{k} \Omega$ over the humidity range from $45 \%$ to $85 \%$. In our work, the obtained resistance change was in the range from $2.5 \mathrm{M} \Omega$ to 5 $\mathrm{k} \Omega$ under the same conditions.

Long term stability measurements were performed for all three sensors after 21 months from their fabrication. The measurements showed a decrease of capacitance response by an order of magnitude, which is not that significant considering their total response.

Response and recovery time is one of the most important figures of merit of humidity sensors, especially in commercial settings. Fig. 4(b) and 5 also show the response-recovery characteristics of the GO based humidity sensors. The time taken by a sensor to reach $90 \%$ of the final capacitance change was defined as the response time in the case of adsorption and recovery time in the case of desorption. The measured average response and recovery times were $30 \mathrm{~s}$ and $150 \mathrm{~s}$, respectively, for all fabricated sensors. This could be explained by different speeds at which the humidity was introduced and removed from the chamber (i.e., the plastic box depicted in Fig. (3)). The humidity was introduced into the chamber by an aerosol device, whereas the humidity exhaustion was performed by self-drying in laboratory atmosphere, similar to previous reports [13]. However, the realized sensor had much higher sensitivity. The rapid response-recovery behavior benefited from the porous structure, hydrophilic functional groups, and large inter-layer space of the GO film.

Hysteresis is one of the most important performance metrics of humidity sensors. Hysteresis leads to the measurement errors because different capacitances (i.e., RH readouts) could be obtained at the same $\mathrm{RH}$ depending on whether $\mathrm{RH}$ increases or decreases. Fig. 6 shows the hysteresis curve in the adsorption and desorption phase of the fabricated GO sensors.
The humidity hysteresis characteristic of the sensors was measured by increasing the RH from 55\% to $95 \%$ and then decreasing the $\mathrm{RH}$ back to $55 \%$. RH was measured by the commercial sensor which has a hysteresis width $\Delta \mathrm{RH} \sim \pm 1 \%$. The maximum hysteresis width of the fabricated sensors was $\Delta \mathrm{RH} \sim 10 \%$. This indicates that further improvements would be needed if the high sensitivity of the presented sensors were to be used in commercial applications.

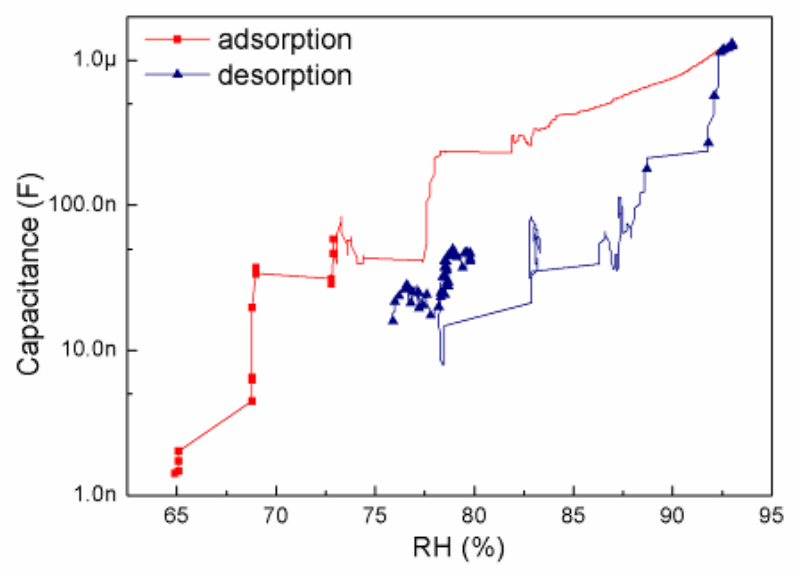

Fig. 6. Humidity hysteresis curves of the GO based sensor

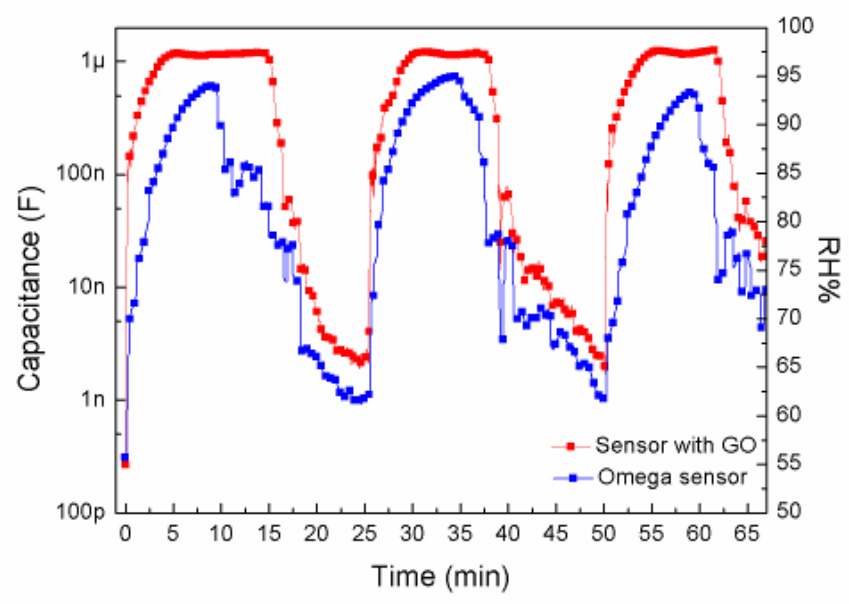

Fig. 7. Repeatability of the GO sensors compared to a commercial sensor (with scale on the right) over three response/recovery cycles.

Fig. 7 shows the repeatability measurement of one of the fabricated GO sensors. The repeatability of the GO sensors was tested by exposing the sensors to three alternating $\mathrm{RH}$ cycles between $55 \% \mathrm{RH}$ and $95 \% \mathrm{RH}$. During the response/recovery cycles, the capacitance response was highly repeatable demonstrating the advantage of the sensors in possible sensor applications. The fabricated sensors compared favorably to the used commercial sensor both in terms of repeatability and sensing performances.

Sensitivity $(S)$ used to characterize the sensor performance is defined as:

$$
S=\frac{\Delta C}{\Delta R H}
$$

where $\Delta C$ is the sensor response change of capacitance and 
$\triangle R H$ is the RH change. In the present case, the sensitivity was $\sim 40 \mathrm{nF} / \% \mathrm{RH}$. The sensing properties of the proposed sensor are comparable to previously demonstrated capacitive-type humidity GO sensors realized in different technologies [11, $17,18,19,20,23,24]$ or with different sensing materials $[4$, 25]. The main advantage of the presented sensor is its very large change of capacitance with humidity, as shown in Table 1. The fabrication procedure was also found to provide a reproducible sensing property which is of the utmost importance in the possible applications of the realized sensors.

TABLE I

PERFORMANCE OF THE SENSORS PRESENTED IN THIS WORK COMPARED TO THE STATE-OF-THE-ART SENSORS

\begin{tabular}{|c|c|c|c|c|}
\hline $\begin{array}{l}\text { Sensing } \\
\text { material }\end{array}$ & $\begin{array}{c}\text { Fabrication } \\
\text { method }\end{array}$ & $\begin{array}{l}\text { Measurement } \\
\text { range }(\% \mathrm{RH})^{\mathrm{a}}\end{array}$ & $\begin{array}{l}\text { Sensitivity } \\
(\mathrm{pF} / \% \mathrm{RH})\end{array}$ & Reference \\
\hline GO & $\begin{array}{l}\text { Ink-jet } \\
\text { printing }\end{array}$ & $55-95$ & 40000 & this work \\
\hline $\mathrm{ZnO}$ & $\begin{array}{c}\text { CMOS+ } \\
\text { post } \\
\text { process }\end{array}$ & $40-90$ & 3.18 & [4] \\
\hline GO & $\begin{array}{l}\text { Drop } \\
\text { casting }\end{array}$ & $15-95$ & 46.25 & [5] \\
\hline $\mathrm{rGO} / \mathrm{SnO} 2$ & $\begin{array}{l}\text { Hydro } \\
\text { thermal } \\
\text { synthesis }\end{array}$ & $11-97$ & 1604.89 & [18] \\
\hline $\begin{array}{c}\text { GO/MWC } \\
\text { NT }\end{array}$ & $\begin{array}{l}\text { magnetro } \\
\text { n } \\
\text { sputtering } \\
\text { + drop } \\
\text { casting }\end{array}$ & $11-97$ & 7980 & [19] \\
\hline GO/PDDA & $\begin{array}{l}\text { LbL self- } \\
\text { assembly }\end{array}$ & $11-97$ & 1552.3 & [20] \\
\hline GO & $\begin{array}{c}\text { Simulatio } \\
\mathrm{n}\end{array}$ & $0-100$ & 7680 & [21] \\
\hline
\end{tabular}

The influence of bending on sensors response was also investigated. Sensors were bent around a cylinder with a radius of $3.5 \mathrm{~mm}$ encompassing an angle of $120^{\circ}$ and exposed to the same humidity tests. The obtained results were almost identical compared to that without bending, as shown in Fig. 8. This represents an important advantage of the proposed sensors for simple monitoring of humidity because they can be placed on almost any surface without affecting their response.

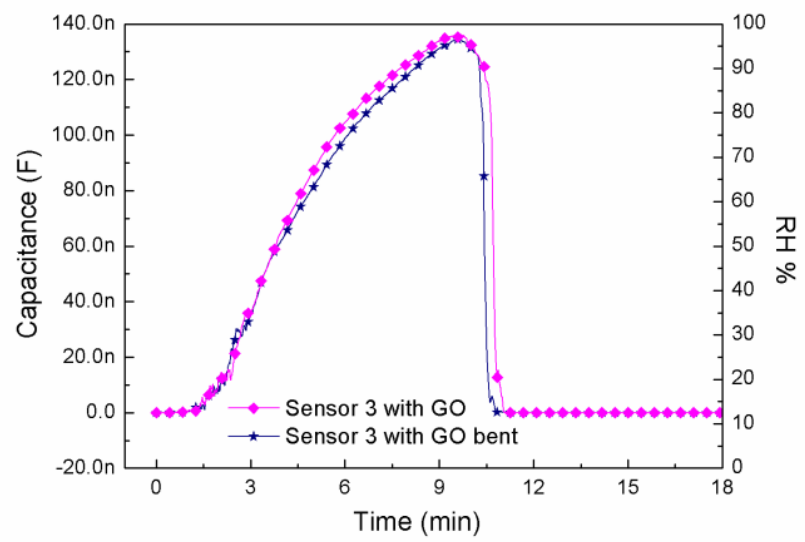

Fig. 8. The humidity measurements performed on one of the sensors without (the magenta line) and with (the blue line) bending.

\section{CONCLUSIONS}

The capacitive interdigitated GO based humidity sensors were fabricated on flexible foil by combining ink-jet printing and spin coating. The sensors comprised interdigitated electrodes made by ink-jet printing of Ag nanoparticle ink and a sensing layer made by spin coating of GO ink. Application of additive ink-jet printing process reduced costs and provided good mechanical properties. Flexible substrate and GO used in the presented sensors enable simple monitoring of humidity in various environments. The humidity sensing properties of the fabricated GO based sensors were investigated by exposing the sensors to humidity in the range 55-95\% RH at room temperature. The sensors exhibited excellent sensitivity in the investigated range of humidity, changing the capacitance by almost 5 orders of magnitude (from $43 \mathrm{pF}$ to $1.6 \mu \mathrm{F}$ ).

\section{REFERENCES}

[1] L. Gu, Q. A. Huang, M. Qin, "A Novel Capacitive-Type Humidity Sensor Using CMOS Fabrication Technology," Sensors and Actuators B: Chemical, vol. 99, pp. 491-498, 2004, DOI: 10.1016/j.snb.2003.12.060.

[2] M. Maksimovic, G. M. Stojanovic, M. Radovanovic, M. Malešev, V. Radonjanin, G. Radosavljevic, W. Smetana, "Application of a LTCC sensor for measuring moisture content of building materials," Construction and Building Materials, vol. 26, pp. 327-333, 2012, DOI: 10.1016/j.conbuildmat.2011.06.029.

[3] A. Oprea, J. Courbat, N. Barsan, D. Briand, N. F. De Rooij, U. Wemar, "Temperature, humidity and gas sensors integrated on plastic foil for low power application," Sensors and Actuators B: Chemical, vol. 140, pp. 227-232, 2009, DOI: 10.1016/j.snb.2009.04.019.

[4] M. Z. Yang, C. L. Dai, C. C. Wu, "Sol-gel zinc oxide humidity sensors integrated with a ring oscillator circuit on-a-chip," Sensors, vol. 14, pp. 20360-20371, 2014, DOI: 10.3390/s141120360.

[5] T. Qiang, C. Wang, M.-Q. Liu, K.K. Adhikari, J.-G. Liang, L. Wang, Y. Li, Y.-M. Wu, G.-H. Yang, F.-Y. Meng, J.-H. Fu, Q. Wu, N.-Y. Kim, Z. Yao, "High-Performance porous MIM-type capacitive humidity sensor realized via inductive coupled plasma and reactive-Ion etching," Sensors and Actuators, B: Chemical, vol. 258, pp. 704-714, 2018, DOI: 10.1016/j.snb.2017.11.060.

[6] M. Sasikumar, N.P. Subiramaniyam, "Microstructure, electrical and humidity sensing properties of $\mathrm{TiO} 2 /$ polyaniline nanocomposite films prepared by sol-gel spin coating technique," Journal of Materials Science: Materials in Electronics, pp. 1-8, 2018, DOI: 10.1007/s10854018-8697-9.

[7] Z. Wang, X. Fan, C. Li, G. Men, D. Han, F. Gu, "Humidity-Sensing Performance of 3DOM WO3 with Controllable Structural Modification," ACS Applied Materials and Interfaces, vol. 10, no. 4, pp. 3776-3783, 2018, DOI: 10.1021/acsami.7b17048.

[8] J. Zhao, N. Li, H. Yu, Z. Wei, M. Liao, P. Chen, S. Wang, D. Shi, Q. Sun, G. Zhang, "Highly Sensitive MoS2 Humidity Sensors Array for Noncontact Sensation," Advanced Materials, vol. 29, no. 34, art. no. 1702076, 2017, DOI: 10.1002/adma.201702076.

[9] Z. Duan, M. Xu, T. Li, Y. Zhang, H. Zou, "Super-fast response humidity sensor based on $\mathrm{La} 0.7 \mathrm{Sr} 0.3 \mathrm{MnO} 3$ nanocrystals prepared by PVPassisted sol-gel method," Sensors and Actuators, B: Chemical, vol. 258, pp. 527-534, 2018, DOI: 10.1016/j.snb.2017.11.169.

[10] B. Gu, C.Y. Aung, P.H.J. Chong, Y.L. Guan, K.-T. Yong, "Reversible and Fast Responsive Optical Fiber Relative Humidity Sensor Based on Polyelectrolyte Self-Assembly Multilayer Film," IEEE Sensors Journal, vol. 18, no. 3, art. no. 8118147, pp. 1081-1086, 2018, DOI: 10.1109/JSEN.2017.2776398.

[11] H. Bi, K. Yin, X. Xie, J. Ji, S. Wan, L. Sun, Terrones M., Dresselhaus M. S., "Ultrahigh humidity sensitivity of graphene oxide," Scientific Reports, vol. 3, Art. No. 2714, 2013, DOI: 10.1038/srep02714.

[12] H. Chi, J. Liu, F. Wang, C. He, "Highly Sensitive and Fast Response Colorimetric Humidity Sensors Based on Graphene Oxides Film," ACS 
Appl. Mater. Interfaces, vol. 7, no. 36, pp. 19882-19886, 2015, DOI: 10.1021/acsami.5b06883.

[13] Y. Yao, X. Chen, H. Guo, Z. Wu, X. Li, "Humidity sensing behaviors of graphene oxide-silicon bi-layer flexible structure," Sensors and Actuators B: Chemical, vol. 161, pp. 1053- 1058, 2012, DOI: 10.1016/j.snb.2011.12.007.

[14] L. Guo, H. B. Jiang, R. Q. Shao, Y. L. Zhang, S. Y. Xie, J. N. Wang, X. B. Li, F. Jiang, Q. D. Chen, T. Zhang, H. B. Sun, "Two-beam-laser interference mediated reduction, patterning and nanostructuring of graphene oxide for the production of a flexible humidity sensing device," Carbon, vol. 50, pp. 1667-1673, 2012, DOI: 10.1016/j.carbon.2011.12.011.

[15] P. G. Su, Z. M. Lu, "Flexibility and electrical and humidity-sensing properties of diamine functionalized graphene oxide films," Sensors and Actuators B: Chemical, vol. 211, pp. 157-163, 2015, DOI: 10.1016/j.snb.2015.01.089.

[16] D. Zhang, J. Tong, B. Xia, "Humidity-sensing properties of chemically reduced graphene oxide/polymer nanocomposite film sensor based on layer-by-layer nano self-assembly," Sensors and Actuators B: Chemical, vol. 197, pp. 66-72, 2014, DOI: 10.1016/j.snb.2014.02.078.

[17] R. Gao, D. F. Lu, J. Cheng, Y. Jiang, L. Jiang, Z. M. Qi, "Humidity sensor based on power leakage at resonance wavelengths of a hollow core fiber coated with reduced graphene oxide," Sensors and Actuators B: Chemical, vol. 222, pp. 618-624, 2016, DOI: 10.1016/j.snb.2015.08.108.

[18] D. Zhang, H. Chang, P. Li, R. Liu, Q. Xue, "Fabrication and characterization of an ultrasensitive humidity sensor based on metal oxide/graphene hybrid nanocomposite," Sensors and Actuators B: Chemical, vol. 225, pp. 233-240, 2016, DOI: 10.1016/j.snb.2015.11.024.

[19] X. Li, X. Chen, X. Chen, X. Ding, X. Zhao, "High-sensitive humidity sensor based on graphene oxide with evenly dispersed multiwalled carbon nanotubes," Materials Chemistry and Physics, vol. 207, pp. 135140, 2018, 10.1016/j.matchemphys.2017.12.033.

[20] D. Zhang, J. Tong, B. Xia, Q. Xue, "Ultrahigh performance humidity sensor based on layer-by-layer self-assembly of graphene oxide/polyelectrolyte nanocomposite film," Sensors and Actuators B: Chemical, vol. 203, pp. 263-270, 2014, 10.1016/j.snb.2014.06.116.

[21] R. Guo, W. Tang, C. Shen, X. Wang, "High sensitivity and fast response graphene oxide capacitive humidity sensor with computer-aided design," Computational Materials Science, vol. 111, pp. 289-293, 2016, 10.1016/j.commatsci.2015.09.032.
[22] C. L. Zhao, M. Qin, W. H. Li, Q. A. Huang, "Enhanced Performance of a CMOS Interdigital Capacitive Humidity Sensor by Graphene Oxide," Solid-State Sensors, Actuators and Microsystems Conference (TRANSDUCERS), vol. 16, pp. 1954-1957, 2011, DOI: 10.1109/TRANSDUCERS.2011.5969243.

[23] P. G. Su, W. L. Shiu, M. S. Tsai, "Flexible humidity sensor based on Au nanoparticles/graphene oxide/thiolated silica sol-gel film," Sensors and Actuators B: Chemical, vol. 216, pp. 467-475, 2016, DOI: 10.1016/j.snb.2015.04.070.

[24] Y. Yao, X. Chen, H. Guo, Z. Wu, "Graphene oxide thin film coated quartz crystal microbalance for humidity detection," Applied Surface Science, vol. 257, pp. 7778-7782, 2011, DOI: 10.1016/j.apsusc.2011.04.028.

[25] F. Molina Lopez, D. Briand, N. F. De Rooij, "All additive inkjet printed humidity sensors on plastic substrate," Sensors and Actuators B: Chemical, vol. 166- 167, pp. 212- 222, 2012, DOI: 10.1016/j.snb.2012.02.042.

[26] J. Weremczuk, G. Tarapata, R. Jachowicz, "Humidity sensor printed on textile with use of ink-jet technology," Procedia Engineering, vol. 47, pp. 1366-1369, 2012, DOI: 10.1016/j.proeng.2012.09.410.

[27] A. De Luca, S. Santra, R. Ghosh, S. Z. Ali, J. W. Gardner, P. K. Guha, F. Udrea, "Temperature-modulated graphene oxide resistive humidity sensor for indoor air quality monitoring," Nanoscale, vol. 8, no. 8, pp. 4565-4572, 2016, DOI: 10.1039/c5nr08598e.

[28] V. Dua, S. P. Surwade, S. Ammu, S. R. Agnihotra, S. Jain, K. E. Roberts, S. Park, R. S. Ruoff, S. K. Manohar, "All-Organic Vapor Sensor Using Inkjet-Printed Reduced Graphene Oxide," Angewandte Chemie International Edition, vol. 49, no. 12, pp. 2154-2157, 2010, DOI: 10.1002/anie.200905089.

[29] GTS flexible materials, available at: http://www.gts-flexible.com/home/

[30] Dimatix Inc., Dimatix Materials Printer DMP-3000, avaliable at: www.dimatix.com

[31] OMEGA Humidity probe, available at: http://www.omega.com/

[32] Q. Wang, Y. Z. Pan, S. S. Huang, S. T. Ren, P. Li, J. J. Li, "Resistive and capacitive response of nitrogen-doped $\mathrm{TiO} 2$ nanotubes film humidity sensor," Nanotechnology, vol. 22, no. 2, 2011, DOI: 10.1088/0957-4484/22/2/025501.

[33] G. Naik, S. Krishnaswamy, "Room-Temperature Humidity Sensing Using Graphene Oxide Thin Films," Graphene, vol. 5, no. 1, 2016, DOI: 10.4236/graphene.2016.51001. 